\title{
Assessment and management of minor burns in children
}

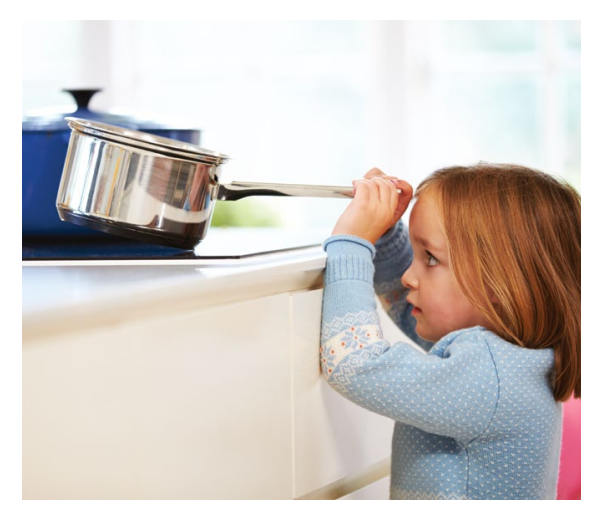

CPD

Sonia Tran, Madeleine A Jacques, Andrew JA Holland

\section{Background}

Approximately $1 \%$ of the Australian and New Zealand population seeks medical assistance for a burn injury each year, and many patients presenting with burns are children. Minor burns that do not meet referral criteria can be managed by the family general practitioner (GP). If there are any concerns about the injury or progress of the burn wound healing, GPs are encouraged to contact their local burns service for advice.

\section{Objective}

The aim of this article is to provide primary healthcare clinicians with a summary of the acute management of minor burns in children.

\section{Discussion}

Effective first aid for burns will minimise burn progression and alleviate pain. Appropriate wound care will promote optimal healing and potentiate favourable outcomes. Although a minor burn may not meet initial referral criteria for transfer to a specialised burn centre, GPs are encouraged to refer if there are any concerns in relation to wound healing, pain management or scarring, or if consultative advice regarding management is required.
BURN INJURIES are common, with approximately $1 \%$ of the Australian and New Zealand population seeking medical assistance for a burn injury each year; many patients with burns are children. ${ }^{1}$ Scald and contact burns account for the majority of paediatric burns in NSW, with friction burns from treadmills increasingly common. ${ }^{2}$ Initial management of a patient presenting with a burn involves performing immediate first aid, conducting primary and secondary surveys and obtaining an accurate and thorough history of both the burn and general medical history. Tetanus immunity should be confirmed, and appropriate vaccination or a booster administered if immunity is unclear or not current. The focus of this article is minor burns, defined as a total body surface area (TBSA) of $<5 \%$, in children aged under 16 years.

\section{First aid for burns}

The aim of first aid is to halt the burn process and to cool the burn wound. ${ }^{1}$ First aid is most effective immediately or at least within the first hours after a burn, helping to reduce production of inflammatory mediators as well as prevent further damage and necrosis of the skin. It usually also provides an added analgesic effect. ${ }^{1,3,4}$
To stop the burn process, the heat source must be eliminated. In a flame burn, this may involve extinguishing the flames by rolling on the ground or by using the 'stop, drop, cover (face) and roll' technique. In a scald burn, clothing must be removed as clothing soaked with hot liquid will continue the burn process. If clothing is adherent to the skin, cutting around the area is sufficient. Chemical burns require copious irrigation with water to mitigate the burn process.

The Australia and New Zealand Burn Association (ANZBA) recommends 20 minutes of cooling with cool running water (approximately $15^{\circ} \mathrm{C}$ ). ${ }^{1}$ Running water is preferable as the flow is constant and the water remains at a consistently cool temperature. Alternative techniques such as spray bottles, bathing the burnt area in water or application of wet towels are less effective, more labour intensive and require frequent monitoring to ensure that the cooling agent has not become warm. Ice or iced water is contraindicated as it increases the risk of hypothermia and leads to vasoconstriction, which in turn may lead to a deeper burn. ${ }^{4}$ It is important to exercise caution when cooling patients, especially at the extremes of age, as they are at particular risk of developing hypothermia. ${ }^{1,3,4}$ Ensuring the unaffected areas remain warm and dry will help 
prevent hypothermia from occurring. Application of cool water should be ceased if any signs of hypothermia are noted. Cooling may be recommenced once the child's body temperature has normalised to ensure adequate first aid. Any jewellery should be removed as this may retain heat or cause constriction when swelling occurs.

\section{Assessment of burn severity}

Assessment of the depth and area of a burn is important to determine whether a patient requires urgent transfer to, or follow-up with, a burns unit as an ambulatory care patient, or may be treated solely by their general practitioner (GP). The size of a burn is also used to calculate intravenous fluid requirements (when the burn is $>10 \%$ TBSA) and helps guide whether patients should be commenced on other supportive treatments such as supplementary nutrition.

\section{Size of burn}

Many techniques may be used to calculate the area of a burn injury, which is usually expressed as a percentage of the patient's TBSA. Traditional methods include the rule of nines chart, Lund and Browder chart and the Palmar Method. The Lund and Browder and rule of nines charts have been designed to take into consideration the different body shapes and proportions of adults and children. The Palmar Method is useful for smaller burns that have a patchy or scattered distribution. Many smartphone applications, such as the NSW Trauma App, ${ }^{5}$ have also been developed to assist clinicians with estimating the extent of a burn. Regardless of the technique used, only the partial-thickness and full-thickness elements of the burn are included in the calculation; epidermal burns (erythemaonly areas) should be excluded. ${ }^{1}$ Many scalp burns require shaving of the hair to ascertain the extent of the burn.

\section{Burn depth}

The depth of a burn will vary depending on the mechanism of the burn, duration of exposure to the heat source, temperature of the heat source and skin thickness. Burn depth is clinically assessed by examining the skin colour, capillary refill, presence of blistering and sensation. Superficial epidermal burns consist of erythema only, whereas superficial dermal burns are usually pink and painful under blistered skin. Mid-dermal burns are often darker pink with a sluggish capillary refill. Deep dermal burns appear mottled with fixed staining and have no capillary refill. Full thickness burns are white, feel leathery and sensation is absent (Table 1). ${ }^{2}$ Burns are dynamic and may evolve after the initial assessment. It is important that a burn is reviewed again 2-3 days later to ensure that it remains appropriate for ambulatory care management, either solely by the patient's GP or in conjunction with a burns unit.

\section{Table 1. Burn depth and associated characteristics ${ }^{3}$}

\begin{tabular}{|c|c|c|c|c|c|}
\hline & Epidermal & Superficial dermal & Mid dermal & Deep dermal & Full thickness \\
\hline \multicolumn{6}{|l|}{ Example* } \\
\hline Appearance & Erythema, dry & Pink & $\begin{array}{l}\text { Dark pink, hair } \\
\text { follicles intact }\end{array}$ & $\begin{array}{l}\text { Blotchy cherry red } \\
\text { and white, mottled }\end{array}$ & White, brown, black \\
\hline Capillary refill & Present, brisk & Present, brisk & Sluggish & $\begin{array}{l}\text { Significantly delayed } \\
\text { or absent }\end{array}$ & Absent \\
\hline Blisters & No & Present & Present & Variable & Absent \\
\hline Sensation & Painful & Painful & Variable & Absent & Absent \\
\hline $\begin{array}{l}\text { Expected healing } \\
\text { time }\end{array}$ & Within 7 days & Within 14 days $^{\dagger}$ & 10-21 days ${ }^{\dagger}$ & $\begin{array}{l}\text { Requires surgical } \\
\text { intervention }{ }^{\ddagger}\end{array}$ & $\begin{array}{l}\text { Requires surgical } \\
\text { intervention }{ }^{\ddagger}\end{array}$ \\
\hline Scarring & No & $\begin{array}{l}\text { Low risk, may have } \\
\text { colour disparity }\end{array}$ & $\begin{array}{l}\text { High risk if heals for } \\
>14 \text { days }\end{array}$ & High risk & High risk \\
\hline
\end{tabular}

*Note: Although the photos illustrate burns that are of fairly uniform depth, burns are often heterogenous 


\section{When to refer}

A burn may be considered minor if it does not meet agreed referral criteria. ${ }^{3}$ ANZBA recommends referral to a specialised burns unit for the following burns in children: ${ }^{1}$

- burns (partial or full thickness) of $>5 \%$ TBSA

- burns to specific areas such as the face, hands, feet, perineum and genitalia and across major joints

- chemical burns

- electrical burns including lightning strikes

- burns associated with trauma

- burns with associated inhalation injuries

- circumferential burns of the limbs or chest

- burns in patients with pre-existing medical disorders that could adversely affect patient care and outcomes, such as diabetes or neurological disability

- suspected non-accidental injury (eg assault or self-inflicted) or social situation concerns warranting specialist input; this should be a consideration in any paediatric patient presenting with a burn if the history does not fit with the clinical presentation

- burns in very young children (aged $<1$ year).

Some minor burns do not meet the referral guidelines but would warrant referral to a specialised burns unit. One such example would be a smaller-sized deep dermal or full-thickness burn that will require skin grafting to heal and should be referred in a timely manner to a specialist paediatric burns service. Other examples include burns that have not healed within 10 days, burns with signs of infection and healed burns that have developed significant scarring. ${ }^{4}$

The ambulatory care management of a burn varies across specialised burns units throughout Australia and needs to consider the patient's age; comorbidities; home situation; burn depth, size and location; availability of dressings and pain relief requirements for procedures including cleansing. ${ }^{4}$ Collaboration with the nearest specialised burns unit will provide assistance with formulation of an individualised management plan and is highly recommended if there are any concerns about the patient or their management. Digital photography or media protocols differ between burn units and should be discussed with the unit as well as ensuring patient, parent or guardian consent has also been obtained.

\section{Management of a burn wound \\ Blister management}

Blisters occur when the epidermis separates from the deeper layers of dermis. Blister management is guided by a specialist's or unit's preference, and there is currently no universally accepted approach. Some of the reasons a clinician may advocate for debridement or aspiration of blister fluid include pain relief, to remove non-viable tissue (decreasing potential infection risk), improve movement of joints (for blisters overlying joints) and to allow for assessment of the burn wound and depth. ${ }^{3,6}$

\section{Dressings}

An ideal dressing for a burn wound promotes wound healing, provides topical antimicrobial cover and is non-adherent, making removal of dressings less traumatic and more tolerable. ${ }^{7,8}$ The aim is to provide an environment that encourages the burn to heal within 14 days, thereby reducing the risk of poor scarring. ${ }^{9}$

Dressing recommendations vary among burn specialists and between burns units. The types of dressings commonly applied and the rationale for their use have been summarised in Table 2 . This should only be used as a guide, and discussion with your nearest burns unit is recommended if there is any uncertainty.

\section{Dressings tips and tricks}

Certain areas of the body can be more difficult to dress and keep intact, particularly in children, who may not be compliant with the application, maintenance or removal of dressings. In the younger age group, secondary dressings for retention are recommended. We provide examples of how the authors' burns unit would dress areas such as the head, trunk, hand and fingers in Figure 1.

\section{Other considerations}

Protection of a recently healed burn

A burn injury may cause damage to the skin's sebaceous glands, leading to a reduction in the skin's natural moisture. ${ }^{4}$ Once healed, regular application of a simple moisturiser such as sorbolene (containing purified water, glycerine and mineral oils) will help prevent breakdown of a recently healed burn. Showering or bathing with a non-soap based cleanser or simple moisturiser is recommended to prevent skin dryness. Burns also lead to loss of melanocytes and changes in melanin production, resulting in pigment changes in the skin at the site of the burn. While this often improves over time, parents should be warned of this phenomenon and encourage their children to use sunscreen or avoid direct exposure to sunlight. ${ }^{10,11}$

\section{Pruritis}

Pruritis may occur as part of the healing process after a burn and may persist once the burn wound has re-epithelialised. The severity and frequency of itch is not necessarily an indication of burn depth or size, and patients may feel an itch on the burn itself, at the skin graft site or over the donor site. ${ }^{1}$ Management options include oral antihistamines and, once healed, topical treatment such as moisturising and massaging, and pressure using tubular bandages or custom-made pressure garments provided by physiotherapists or occupational therapists.

\section{Antibiotics}

Prophylactic antibiotics are not routinely prescribed to patients with burns in the authors' burns unit, unless there is clinical evidence of an acute infection. ${ }^{4}$ A wound swab is recommended if there are signs of an infection, and antibiotics should be chosen on the basis of sensitivities. Consultation with the infectious diseases team is recommended.

\section{Analgesia}

Burn-related procedures, from removal of dressings to deroofing of blisters, can 
be painful and anxiety provoking. When a patient has planned follow-up at your practice, it may be helpful to advise analgesia (eg paracetamol, ibuprofen or codeine, as appropriate) be taken 30 minutes prior to the appointment. Consideration of procedural preparation and intraprocedural distraction can be useful in reducing patient anxiety, especially in the younger patient cohort. If your facility is unable to provide adequate analgesia or comfort/ distraction measures, referral to your nearest burns unit is strongly recommended.

\section{Key points}

- Minimise burn progression by providing effective first aid - 20 minutes of cool running water and removal of heat source (eg clothing).

- A complete burn assessment includes a primary survey and detailed history of the burn injury.

- Call emergency services on Triple Zero (000) if the burn is life or limb threatening or if $>10 \%$ TBSA.

- Refer to your state's specialist paediatric burns unit if any suspicion of non-accidental injury or if the burn meets your state's referral criteria.
- Deep burns (deep dermal or full thickness) or burns that have not healed within 7-10 days should be referred to your state's paediatric burns unit.

- Apply a burns dressing (Table 2) to help promote wound healing.

- Procedural preparation/distraction and adequate analgesia may reduce patient trauma and anxiety.

- Protect a recently healed burn with sun protection, regular moisturisation, avoidance of soap washes and alleviation of pruritus.

\begin{tabular}{|c|c|c|c|c|}
\hline Dressing type & Rationale & Indication & Application & Precautions \\
\hline $\begin{array}{l}\text { Foam } \\
\text { Also available with silver }\end{array}$ & $\begin{array}{l}\text { - Non-adherent } \\
\text { - Highly absorbable } \\
\text { - Easily conformable }\end{array}$ & - Superficial burns & $\begin{array}{l}\text { - Apply to clean wound } \\
\text { - Can leave intact for } \\
\text { 5-7 days }\end{array}$ & $\begin{array}{l}\text { - Not recommended if } \\
\text { infection present }\end{array}$ \\
\hline Hydrocolloid & $\begin{array}{l}\text { - Aids autolysis of } \\
\text { devitalised tissue } \\
\text { - Moderately absorbent } \\
\text { - Conformable } \\
\text { - Provides moist wound } \\
\text { environment }\end{array}$ & $\begin{array}{l}\text { - Superficial to } \\
\text { mid-dermal burns }\end{array}$ & $\begin{array}{l}\text { - Apply to clean wound, } \\
\text { leaving a border of } \\
\text { dressing around wound } \\
\text { - Can leave intact for } \\
5 \text { days }\end{array}$ & $\begin{array}{l}\text { - Not recommended if } \\
\text { infection present or in } \\
\text { highly exudative wounds }\end{array}$ \\
\hline $\begin{array}{l}\text { Paraffin gauze } \\
\text { Also available with } \\
\text { chlorhexidine }\end{array}$ & $\begin{array}{l}\text { - Non-adherent } \\
\text { - Conformable } \\
\text { - Antiseptic if } \\
\text { chlorhexidine } \\
\text { impregnated }\end{array}$ & - Dermal burns & $\begin{array}{l}\text { - Apply to clean wound } \\
\text { - Change every } 1-3 \text { days } \\
\text { - Can leave chlorhexidine- } \\
\text { impregnated gauze } \\
\text { intact for up to } 5 \text { days }\end{array}$ & $\begin{array}{l}\text { - Soak off if adherent } \\
\text { to wound }\end{array}$ \\
\hline
\end{tabular}

\section{Silver}

Nanocrystalline silvercoated mesh with inner rayon layer
- Broad spectrum antimicrobial protection (silver toxic to micro-organisms)

- May decrease exudate formation
- Dermal to full-thickness burns

- Infected wounds
excess water, apply either side

- Leave intact for 3-4 days (some types may be left intact for 7 days)
- Dermal to full-thickness - Apply to clean burns

- Infected wounds wound daily
- Not recommended in most units - labour intensive, may change appearance of wound micro-organisms)

May leave temporary stain on skin

Heavy exudate may

- Absorbs exudate, facilitates debridement
- Dermal to full-thickness burns
- Apply to clean wound, leaving a $2-5 \mathrm{~cm}$ border around wound, cover with secondary dressing, leave intact until wound heals 


\section{Specialist paediatric burns units in Australia}

\section{Australia and New Zealand}

- Australian \& New Zealand Burn Association, https://anzba.org.au/ resources/burn-units

\section{NSW and ACT}

- Burns Unit, The Children's Hospital Westmead, Sydney, www.schn.health. nsw.gov.au/find-a-service/burns/chw

- Agency for Clinical Innovation, Burn Injury Network, www.aci.health.nsw. gov.au/networks/burn-injury

\section{Vic}

- Burns Unit, The Royal Children's Hospital, Melbourne, www.rch.org.au/ burns/contact_us

- Victorian Adult Burns Service at The Alfred, www.vicburns.org.au

\section{QId}

- Pegg Leditschke Children's Burns Centre, Queensland Children's Hospital, Brisbane, www.childrens. health.qld.gov.au/service-burns

\section{SA}

- Burns Service, Women's and Children's Hospital, Adelaide, www.wch.sa.gov. $\mathrm{au} /$ services/az/divisions/psurg/burns/ index.html

\section{WA}

- Perth Children's Hospital Burns Service, Perth, https://pch.health.wa.gov.au/ Our-services/Burns

\section{Tas}

- Tasmanian Burns Unit, Royal Hobart Hospital, Hobart, www.dhhs.tas.gov. $\mathrm{au} /$ service_information/services_files/ $\mathrm{RHH} /$ treatments_and_services/burns

\section{NT}

- Royal Darwin Hospital, Darwin 0889228888

\section{Authors}

Sonia Tran BMed, MS (Surgical Sciences), Burns Fellow, The Children's Hospital at Westmead Burns Research Institute, NSW

Madeleine A Jacques BNursing, BAppSc (Occupational Therapy), MNursing (Nurse Practitioner), GradDipNursing (Burns), Nurse Practitioner, The Children's Hospital at Westmead Burns Research Institute, NSW
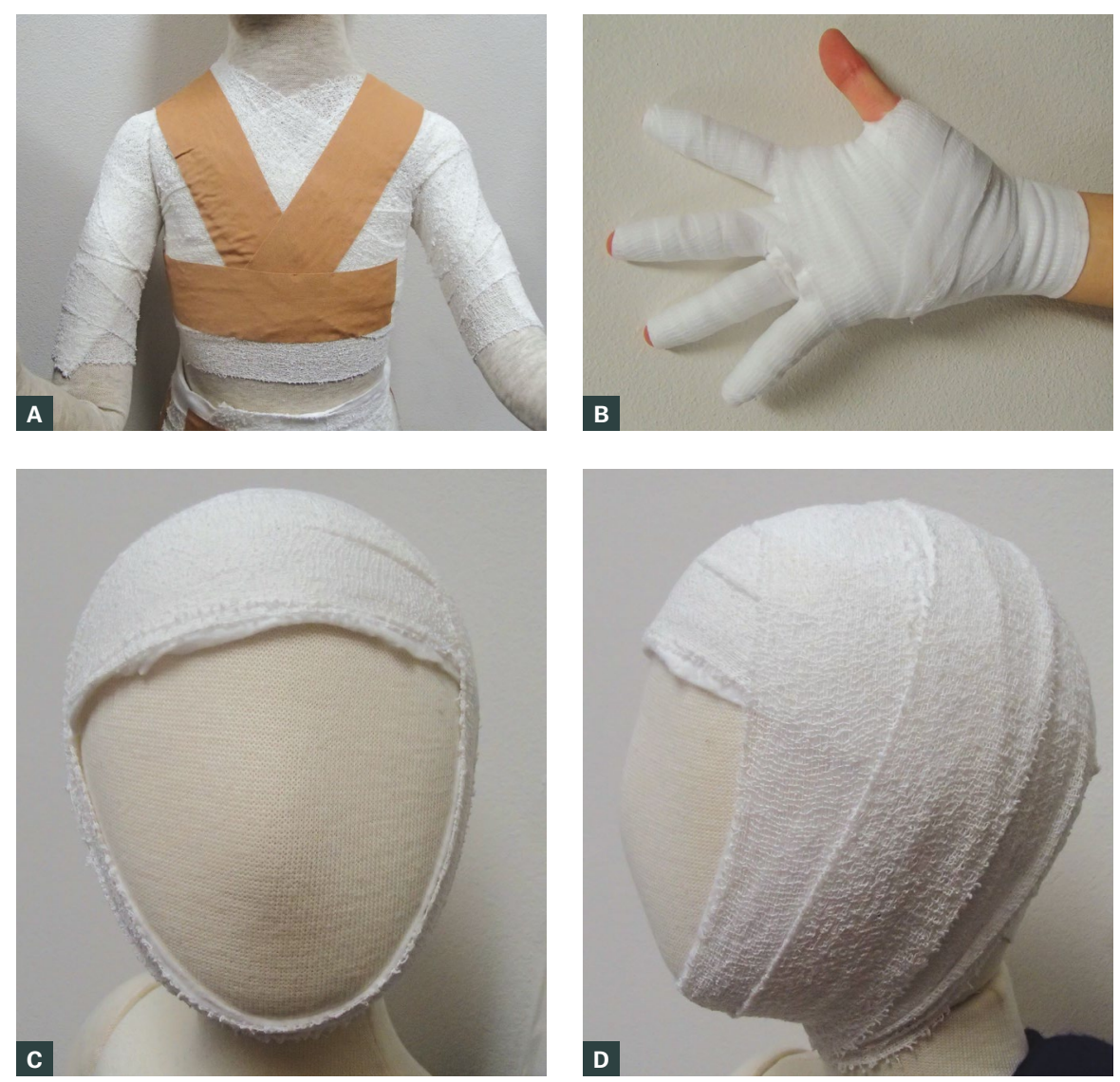

Figure 1. Example of dressing methods for difficult areas

A. Dressings to burns of the upper arm or shoulder (or upper thigh and hip) are more likely to remain intact if extended around the torso; $\mathbf{B}$. Hand and finger dressing; fingers are dressed individually to ensure burnt surfaces are separated; C,D. Head bandages can be reinforced with a bandage wrapped around the face to prevent the head bandage from slipping off.

Andrew JA Holland BSc (Hons), MBBS, PhD, FRCS (Eng), FRACS (Paed), FACS, Director, The Children's Hospital at Westmead Burns Research Institute, NSW; Professor of Paediatric Surgery, University of Sydney, NSW. andrew.holland@health.nsw.gov.au Competing interests: None.

Funding: None.

Provenance and peer review: Commissioned, externally peer reviewed.

\section{References}

1. Australian \& New Zealand Burn Association. Emergency management of severe burns: Course manual. 17th ed. Albany Creek, QLD: ANZBA, 2013.

2. Australian \& New Zealand Burn Association. BRANZ Burns Registry of Australia and New Zealand: Annual Report 1st July 2016 - 30th June 2017. Melbourne: ANZBA, 2017.

3. NSW Agency for Clinical Innovation. Minor burn management: Clinical guidelines. 4th edn. Chatswood, NSW: ACl, 2019.

4. NSW Agency for Clinical Innovation. Burn patient management: Summary of evidence. 4th edn. Chatswood, NSW: ACl, 2018.
5. NSW Agency for Clinical Innovation. NSW Trauma App. Chatswood, NSW: ACl, 2018. Available at https://itunes.apple.com/au/ app/nsw-trauma/id1030612905 [Accessed 16 July 2019].

6. Douglas HE, Wood F. Burns dressings. Aust Fam Physician 2017;46(3):94-97.

7. Carta T, Gawaziuk JP, Diaz-Abele J, Liu S, Jeschke M, Logsetty S. Properties of an ideal burn dressing: A survey of burn survivors and front-line healthcare providers. Burns 2019;45(2):364-68. doi: 10.1016/j.burns.2018.09.021.

8. Selig HF, Lumenta DB, Giretzlehner M, Jeschke MG, Upton D, Kamolz LP. The properties of an 'ideal' burn wound dressing - What do we need in daily clinical practice? Results of a worldwide online survey among burn care specialists. Burns 2012;38(7):960-66. doi: 10.1016/j.burns.2012.04.007.

9. Chipp E, Charles L, Thomas C, Whiting K, Moiemen N, Wilson Y. A prospective study of time to healing and hypertrophic scarring in paediatric burns: Every day counts. Burns Trauma 2017;5(3):1-6. doi: 10.1186/s41038-016-0068-2. 
10. de Chalain TM, Tang C, Thomson HG.

Burn area colour changes after superficial

burns in childhood: Can they be predicted?

J Burn Care Rehabil 1998;19(1 Pt 1):39-49.

doi: 10.1097/00004630-199801000-00010.

11. Callender VD, St Surin-Lord S, Davis EC,

Maclin M. Post-inflammatory hyperpigmentation:

Etiologic and therapeutic considerations.

Am J Clin Dermatol 2011;12(2):87-99.

doi: 10.2165/11536930-000000000-00000. 